OPEN ACCESS

Edited by: Abanoub Riad,

Masaryk University, Czechia

Reviewed by:

Elham Kateeb,

Al-Quds University, Palestine

Hashaam Akhtar,

Yusra Institute of Pharmaceutical

Sciences Islamabad, Pakistan

${ }^{*}$ Correspondence: Mohammed Khaled Al-Hanawi

mkalhanawi@kau.edu.sa

TORCID:

Mohammed Khaled Al-Hanawi orcid.org/0000-0002-8419-2219

Noor Alshareef orcid.org/0000-0003-2377-8811

Rehab H. El-Sokkary orcid.org/0000-0002-8135-7671

Specialty section:

This article was submitted to Infectious Diseases - Surveillance,

Prevention and Treatment, a section of the journal

Frontiers in Medicine

Received: 22 October 2021 Accepted: 06 December 2021

Published: 10 January 2022

Citation:

Al-Hanawi MK, Alshareef $N$ and El-Sokkary RH (2022) Relief After COVID-19 Vaccination: A Doubtful or Evident Outcome?

Front. Med. 8:800040.

doi: $10.3389 /$ fmed.2021.800040

\section{Relief After COVID-19 Vaccination: A Doubtful or Evident Outcome?}

\author{
Mohammed Khaled Al-Hanawi ${ }^{1,2 * t}$, Noor Alshareef ${ }^{1,2+}$ and Rehab H. El-Sokkary ${ }^{3 \dagger}$ \\ ${ }^{1}$ Faculty of Economics and Administration, Department of Health Services and Hospital Administration, King Abdulaziz \\ University, Jeddah, Saudi Arabia, ${ }^{2}$ Health Economics Research Group, King Abdulaziz University, Jeddah, Saudi Arabia, \\ ${ }^{3}$ Faculty of Medicine, Medical Microbiology and Immunology Department, Zagazig University, Zagazig, Egypt
}

Background: Since development of the first COVID-19 vaccine, the landscape of public confidence in these vaccines is uncertain. Building confidence is crucial for better preparedness of future pandemics. Following the mandatory COVID-19 vaccination policy in the country, the aim of this study was to examine whether the Saudi public feels relieved post-vaccination and to identify the factors predicting such relief.

Methods: An online cross-sectional survey was conducted in July 2021 among COVID-19 vaccine recipients in Saudi Arabia. A multivariable logistic regression analysis was employed to examine and identify the variables associated with feeling relieved post-vaccination.

Results: Most of the respondents (66\%) stated feeling more relieved post-vaccination. Male gender [adjusted odds ratio (AOR): 1.380; 95\% confidence interval (Cl): 0.9811.943], being a student (AOR: 3.902; 95\% Cl: 1.674-9.096), and received two doses of the vaccine (AOR: 2.278; 95\% Cl: 1.630-3.182) were associated with feeling more relieved after getting vaccinated. Respondents who were anxious about the vaccine before receiving it (AOR: 0.220; 95\% Cl: 0.160-0.302), and experienced a severe reaction after vaccination (AOR: 0.288; 95\% Cl: 0.165-0.504) had lower odds of feeling relieved post-vaccination. Respondents who relied on social media as the main source of vaccine-related information and those having no information about the vaccine were also less likely to feel relieved post-vaccination.

Conclusions: Individuals' attitudes toward COVID-19 vaccines may not necessarily alter post-vaccination. Although mandatory vaccination policies can significantly contribute to achieving herd immunity, public confidence toward vaccines might be eroded, which could in turn impose significant challenges in future pandemics efforts.

Keywords: vaccine-related anxiety, trust, immunization program, CovID-19, relief, Saudi Arabia 


\section{INTRODUCTION}

It is well-recognized that mass immunization efforts represent a critical step toward combating the COVID-19 pandemic (1). The development of COVID-19 vaccines has shown the world how substantial funding, research collaboration, and diligence can stimulate innovation to address public needs at a global level and in a short period of time (2). By early March 2021, stringent regulatory agencies worldwide started to authorize several highly effective vaccines. Nevertheless, the challenge of a vaccine-based solution to the COVID-19 pandemic does not end with the development of an effective and safe vaccine, as achieving herd immunity will require the vaccination of a significant proportion of the population (1). Despite the devastating impact COVID-19 has had on people's health and well-being, many remain unwilling to vaccinate against the virus. The wide spread of misinformation, coupled with mistrust in pharmaceutical companies (3-5) and concerns surrounding the safety and efficiency of vaccines (6-8) have been shown to undermine vaccine acceptance (2). Thus, enhancing public trust in COVID-19 vaccines and vaccination in general is as critical as developing effective vaccines (2).

The success of vaccination campaigns is dependent on peoples' trust in the effectiveness and safety of the vaccines, the competence and reliability of the delivering institutions, and the principles and processes underlying government decisions and actions (2). In December 2020, the World Health Organization (WHO) released a safety surveillance manual that provided guidance on many aspects of vaccine global efforts, highlighting the importance of adequate advance planning of immunization campaigns and how to support vaccine safety communication during the COVID-19 pandemic (9). Anxiety-related events that occur soon after COVID-19 vaccination may cause concern among other vaccine recipients and staff members, particularly in a mass vaccination scenario (10). When adverse events were reported related to the $2009 \mathrm{H} 1 \mathrm{~N} 1$ influenza pandemic vaccine, some countries did not provide timely information about the association of the events with the vaccine, causing lack of confidence in the vaccine that subsequently influenced vaccine uptake and communication $(11,12)$. Thus, sustaining trust during a pandemic is critical for health authorities, both if repeated vaccinations are necessary and in preparation for future health emergencies (13).

Willingness to become vaccinated changes over time, and those hesitating are likely to be taking their cues from others (10). For example, a study conducted in the USA showed that $69 \%$ of individuals who had not been vaccinated but lived in a household with someone who had already been vaccinated were willing to vaccinate against COVID-19 as soon as possible; this was also true among those who were not vaccinated but had a close friend or family member outside their households who already received a vaccine. By contrast, only one third of individuals who had a causal connection or no connection to a vaccinated person were willing to receive the vaccine as soon as possible (14). It is suggested that as more individuals are vaccinated, more will be willing to accept vaccination (2). This may reflect that being a recipient of the vaccine gradually becomes the norm and is recognized as the way out of confinement and restriction. Moreover, conformism or "herd behavior" might have a positive influence on the diffusion of vaccination even if population acceptance of the vaccine is modest, which can be attributed to the fact that individuals who were initially wiling to vaccinate may send a positive signal about their beliefs of the safety and efficacy of the vaccine (10).

A survey assessing the acceptability of COVID-19 vaccines among the Saudi population prior to arrival of the vaccine to the country showed that only $48 \%$ of respondents were willing to be vaccinated (15). Another public survey conducted after the rollout of national vaccination program in the country showed an acceptance rate of $60 \%$ (16). As the time of this study, report shows that around $70 \%$ of the population received the COVID-19 vaccine in Saudi Arabia (17). Following mandatory vaccination policies in the country and elsewhere, this study investigated how people feel after receiving the vaccine. Given that individuals' experience with COVID-19 will shape their confidence in other vaccines, and to help promote confidence at this time, it is critical to understand if people feel relieved after receiving the COVID19 vaccine. Therefore, the objective of this study was to examine whether vaccinations made the general Saudi public feel more relieved and to identify the factors predicting such relief. This can shed light on future efforts needed when novel vaccines are introduced in response to pandemics.

\section{MATERIALS AND METHODS \\ Study Design and Sample}

This study used an online cross-sectional survey conducted between 13 and 20 July 2021 among adults aged 18 years or older, who were vaccinated against COVID-19 (one or two doses) and living in the Kingdom of Saudi Arabia (KSA). Participants were asked to participate in a self-administered online questionnaire using SurveyMonkey Inc. (San Mateo, CA, USA). Invitations to participate in the study were distributed to respondents via social media platforms, including Twitter (San Francisco, CA, USA) and WhatsApp Inc. (Mountain View, CA, USA). A simplified snowball sampling technique was used to recruit participants. The online approach was being used to avoid any physical contact. Moreover, an online approach of data collection via social media platforms has been used in several studies during the COVID-19 pandemic, and can be considered, to a great extent, as a credible approach $(6,18,19)$.

We aimed to maximize reach and gather data from as many respondents as possible. According to the latest KSA census, Saudi Arabia has a population of 35,013,414 (20). Using a sample size calculator (21), the representative target sample size was calculated to be 1037 participants, using a margin of error of $\pm 4 \%$, confidence level of $99 \%, 50 \%$ response distribution, and $35,013,414$ people.

Online informed consent was obtained from all participants before proceeding with the questionnaire. The respondents were clearly informed about the aim and objectives of the study, their voluntary participation and their right to withdraw from the study at any time, and that all information would be anonymous and confidential. A total of 1,094 participants completed the 
questionnaire across the 13 regions in the KSA. After excluding responses from participants living outside the KSA and those with missing data on variables of interest, the final sample for analysis comprised responses from 1,058 participants.

The self-reported questionnaire was designed and developed based on similar studies and frameworks to assess potential postvaccination side effects and stress-related information following immunization (22-25). The questionnaire was validated by an expert panel who carefully reviewed the items of the questionnaire and provided feedback and suggestions. The questionnaire was then updated based on their feedback and suggestions. The reliability of the questionnaire was also evaluated using the Cronbach alpha test. Cronbach's alpha coefficient was 0.75 , indicating good internal reliability (26).

The questionnaire consisted of four main sections. The first section gathered information on the respondents' sociodemographic characteristics. The second section gathered information on health behaviors, type of vaccination received, and knowledge and sources of information about COVID19 vaccines. The third section gathered information related to perceptions and beliefs following vaccination. The final section collected information on the reaction after vaccination. The questionnaire was originally written in English and then translated into Arabic. The survey was administered in Arabic.

\section{Measures}

\section{Outcome Measure}

The main outcome variable for this study was relief after receiving the COVID-19 vaccine. To measure relief, participants were asked if they felt relieved after vaccination. The responses to this question were "yes" or "no." This outcome variable was coded as a binary variable, with 0 for those stating not feeling relieved after taking the vaccine and 1 for those stating feeling relieved following vaccination.

\section{Explanatory Variables}

Some explanatory variables were collected and assessed to place the results in context. Respondents were asked about their sociodemographic characteristics, including age, gender, marital status, educational level, and employment status. The age variable was divided into five categories: 18-29 (reference category), $30-39,40-49,50-59$, and $\geq 60$ years. Gender was coded as a binary variable, with 1 for male and 0 for female. Marital status was also captured as a binary variable, with 1 for married and 0 for unmarried (including single, widowed, and divorced). Educational level was divided into three categories: high school or below (reference category), university degree, and postgraduate degree. Employment status was categorized into four groups: government employee (reference group), private sector employee, students, unemployed, and retired.

Respondents were also asked whether they suffer from chronic illness, were smokers, had been infected with COVID-19 before vaccination, were concerned about the COVID-19 vaccine before taking it, their main source of information about COVID-19 vaccines, the type of vaccine received, number of doses received so far, had a COVID-19 breakthrough infection, and if they had any side effects after getting the vaccine.

\section{Statistical Analyses}

Bivariate and multivariable regression analyses were the major analytical tools employed in this study. Bivariate analysis of categorical variables was performed using chi-squared tests to determine the associations between our dependent variable of interest (feeling more relieved after vaccination) and independent variables. A multivariable logistic regression analysis was employed to examine and identify the variables associated with feeling relieved post- vaccination, with the adjusted odds ratio (AOR) and 95\% confidence interval (CI) calculated. All analyses were conducted using STATA 16.1 software (StataCorp LP, Texas, USA).

\section{Ethical Considerations}

All procedures performed in this study involving human participants complied with the institutional and/or national research committee ethical standards and the 1964 Helsinki Declaration and subsequent amendments or equivalent ethical standards. This research has been reviewed and given a favorable opinion by King Abdulaziz University. The study was designed and conducted according to the ethical principles established by King Abdulaziz University. Therefore, ethical approval was obtained from the Biomedical Ethics Research Committee, Faculty of Medicine, King Abdulaziz University (Ref-380-21).

\section{RESULTS}

Table 1 presents the characteristics of participants and the potential factors influencing the feeling of relieved after COVID-19 vaccination. Among the 1,058 respondents, 703 (66.45\%) felt relieved after receiving the vaccine. Most of the respondents were aged below the age of 49 years, married, and had higher education. Approximately half of the respondents were female and employed in the government sector.

One-third of the respondents were suffering from a chronic illness and about one-quarter were smokers. More than half of the participants indicated being anxious about the vaccine before receiving it. Approximately three-quarters of the participants indicated that the official media and scientific or medical websites were their main sources of information about COVID19 vaccines. About half of the respondents had received two doses of the vaccine, while only $7 \%$ stated that they became infected with COVID-19 after vaccination (i.e., "breakthrough" infection). Approximately $10 \%$ of the respondents indicated that they had severe side effects after receiving the vaccine. As shown in Table 1, age, gender, information source about the vaccine, number of doses received, and having side effects after receiving the vaccine were significantly associated with feeling more relieved post-vaccination at the $1 \%$ level.

Table 2 presents the results of logistic regression estimates of factors associated with feeling relieved after COVID-19 vaccination. With increasing age, the participants felt more relieved. Comparing to females, male respondents felt more relieved after vaccination (AOR: 1.380; 95\% CI: 0.981-1.943). Although there were no significant associations with most of the employment status categories, being a student was associated 
TABLE 1 | Frequency distribution and chi-square analysis of post-COVID-19 vaccination relief $(N=1,058)$.

\begin{tabular}{|c|c|c|c|c|c|c|c|}
\hline \multirow[t]{2}{*}{ Variable } & \multicolumn{2}{|c|}{$\begin{array}{l}\text { Not feeling relieved after vaccination } \\
\qquad n=355\end{array}$} & \multicolumn{2}{|c|}{$\begin{array}{l}\text { Feeling relieved after vaccination } \\
\qquad n=703\end{array}$} & \multicolumn{2}{|c|}{ Total (\%) } & \multirow[t]{2}{*}{$P$-value } \\
\hline & $n$ & $\%$ & $n$ & $\%$ & $n$ & $\%$ & \\
\hline \multicolumn{8}{|l|}{ Age (years) } \\
\hline $18-29$ & 54 & 15.21 & 89 & 12.66 & 143 & 13.52 & $0.003^{\star \star \star}$ \\
\hline 30-39 & 135 & 38.03 & 228 & 32.43 & 363 & 34.31 & \\
\hline $40-49$ & 103 & 29.01 & 191 & 27.17 & 294 & 27.79 & \\
\hline $50-59$ & 44 & 12.39 & 110 & 15.65 & 154 & 14.56 & \\
\hline$\geq 60$ & 19 & 5.35 & 85 & 12.09 & 104 & 9.83 & \\
\hline \multicolumn{8}{|l|}{ Gender } \\
\hline Female & 223 & 66.82 & 317 & 45.09 & 540 & 51.04 & $<0.001^{\star \star *}$ \\
\hline Male & 132 & 37.18 & 386 & 54.91 & 518 & 48.96 & \\
\hline \multicolumn{8}{|l|}{ Marital status } \\
\hline Unmarried & 91 & 25.63 & 171 & 24.32 & 262 & 24.76 & \\
\hline Married & 264 & 74.37 & 532 & 75.68 & 796 & 75.24 & 0.641 \\
\hline \multicolumn{8}{|l|}{ Educational level } \\
\hline High school or below & 61 & 17.18 & 168 & 23.90 & 229 & 21.64 & $0.015^{\star \star}$ \\
\hline University degree & 173 & 48.73 & 287 & 40.83 & 460 & 43.48 & \\
\hline Postgraduate degree & 121 & 34.08 & 248 & 35.28 & 369 & 34.88 & \\
\hline \multicolumn{8}{|l|}{ Employment status } \\
\hline Government employee & 181 & 50.99 & 360 & 51.21 & 541 & 51.13 & $<0.001^{\star \star \star}$ \\
\hline Private sector employee & 65 & 18.31 & 96 & 13.66 & 161 & 15.22 & \\
\hline Students & 15 & 4.23 & 55 & 7.82 & 70 & 6.62 & \\
\hline Unemployed & 19 & 5.35 & 91 & 12.94 & 110 & 10.40 & \\
\hline Retired & 75 & 21.13 & 101 & 14.37 & 176 & 16.64 & \\
\hline \multicolumn{8}{|l|}{$\begin{array}{l}\text { Suffer from } \\
\text { chronic illness }\end{array}$} \\
\hline No & 243 & 68.45 & 462 & 65.72 & 705 & 66.64 & 0.373 \\
\hline Yes & 112 & 31.55 & 241 & 34.28 & 353 & 33.36 & \\
\hline \multicolumn{8}{|c|}{ Smoker (cigarettes or shisha) } \\
\hline No & 288 & 81.13 & 510 & 72.55 & 798 & 75.43 & $0.002^{\star \star \star}$ \\
\hline Yes & 67 & 18.87 & 193 & 27.45 & 260 & 24.57 & \\
\hline \multicolumn{8}{|l|}{$\begin{array}{l}\text { Infected with COVID-19 } \\
\text { before vaccination }\end{array}$} \\
\hline No & 301 & 84.79 & 605 & 86.06 & 906 & 85.63 & 0.578 \\
\hline Yes & 54 & 15.21 & 98 & 13.94 & 152 & 14.37 & \\
\hline \multicolumn{8}{|l|}{$\begin{array}{l}\text { Feeling anxious about } \\
\text { the COVID-19 } \\
\text { vaccine before receiving } \\
\text { it }\end{array}$} \\
\hline No & 78 & 21.97 & 425 & 60.46 & 503 & 47.54 & $<0.001^{\star \star \star}$ \\
\hline Yes & 277 & 78.03 & 278 & 39.54 & 555 & 52.46 & \\
\hline \multicolumn{8}{|l|}{$\begin{array}{l}\text { Main source of } \\
\text { information } \\
\text { about COVID-19 vaccines }\end{array}$} \\
\hline $\begin{array}{l}\text { Official media/scientific or } \\
\text { medical websites }\end{array}$ & 243 & 68.45 & 556 & 79.09 & 799 & 75.52 & $<0.001^{\star \star \star}$ \\
\hline Social media platforms & 60 & 16.9 & 73 & 10.38 & 133 & 12.57 & \\
\hline Friends and relatives & 21 & 5.92 & 45 & 6.40 & 66 & 6.24 & \\
\hline Have no information & 31 & 8.73 & 29 & 4.13 & 60 & 5.67 & \\
\hline \multicolumn{8}{|l|}{$\begin{array}{l}\text { Number of doses } \\
\text { received so far }\end{array}$} \\
\hline One & 234 & 65.92 & 304 & 43.24 & 538 & 50.85 & $<0.001^{\star \star \star}$ \\
\hline
\end{tabular}


TABLE 1 | Continued

\begin{tabular}{|c|c|c|c|c|c|c|c|}
\hline \multirow[t]{2}{*}{ Variable } & \multicolumn{2}{|c|}{$\begin{array}{l}\text { Not feeling relieved after vaccination } \\
\qquad n=355\end{array}$} & \multicolumn{2}{|c|}{$\begin{array}{l}\text { Feeling relieved after vaccination } \\
\qquad n=703\end{array}$} & \multicolumn{2}{|c|}{ Total (\%) } & \multirow[t]{2}{*}{$P$-value } \\
\hline & $n$ & $\%$ & $n$ & $\%$ & $n$ & $\%$ & \\
\hline Two & 121 & 34.08 & 399 & 56.76 & 520 & 49.15 & \\
\hline \multicolumn{8}{|c|}{$\begin{array}{l}\text { Had a COVID-19 } \\
\text { breakthrough infection }\end{array}$} \\
\hline No & 324 & 91.27 & 653 & 92.89 & 977 & 92.34 & 0.349 \\
\hline Yes & 31 & 8.73 & 50 & 7.11 & 81 & 7.66 & \\
\hline \multicolumn{8}{|l|}{$\begin{array}{l}\text { Had reaction } \\
\text { to the vaccine }\end{array}$} \\
\hline No side effects at all & 69 & 19.44 & 189 & 26.88 & 258 & 24.39 & $<0.001^{\star \star \star}$ \\
\hline Mild side effects & 138 & 38.87 & 314 & 44.67 & 452 & 42.72 & \\
\hline Moderate side effects & 92 & 25.92 & 153 & 21.76 & 245 & 23.16 & \\
\hline Severe side effects & 56 & 15.77 & 47 & 6.69 & 103 & 9.74 & \\
\hline
\end{tabular}

${ }^{\star \star \star} P<0.01,{ }^{\star \star} P<0.05$

with feeling relieved after vaccination (AOR: 3.902; 95\% CI: 1.674-9.096). Compared to those who were not initially anxious about the vaccine before vaccination, participants who reported being anxious were still not feeling relieved post vaccination (AOR: 0.220; 95\% CI: 0.160-0.302).

Another interesting result was that respondents who relied on social media as the main source of information about the vaccine and those having no information about the vaccine had lower odds of feeling more relieved after vaccination compared with those who relied on official sources and scientific or medical websites. Respondents who received two doses of the vaccine were two times more likely to feel relieved after getting the vaccine compared with those who had received only one dose (AOR: 2.278; 95\% CI: 1.630-3.182). Lastly, those who experienced severe side effects after vaccination had lower odds of feeling more relieved after vaccination compared with those who did not have any side effects at all (AOR: 0.288; 95\% CI: 0.165-0.504).

\section{DISCUSSION}

For COVID-19 vaccine efforts to be successful, the safety and efficacy of the vaccine as well as its wide acceptance should be ensured. To increase public resilience to any myths and rumors surrounding the vaccine and to strengthen further support for vaccination programs, it is important to understand whether or not people feel relieved after receiving the COVID-19 vaccine. Thereby, the aim of this study was to examine post-vaccination relief among the general Saudi population and the contributing factors. It is important to identify factors of relief after being vaccinated to help guide recommendations for encouraging vaccination and preventing the further spread of COVID-19. We found that males, older participants, and those who completed the two-dose vaccination series felt relieved after COVID-19 vaccination. Participants relying on social media as the main source of information about the COVID-19 vaccine and those experiencing serious adverse side effects were less likely to feel relieved post-vaccination.
Studies assessing vaccination acceptance reported that older adults are more likely to accept the COVID-19 vaccine (27). It is thus not surprising that our results showed that as the age of participants increased, the feeling of relief after receiving the vaccine became more common. This study also showed gender differences in feeling relieved about the vaccine post-vaccination, with males being more likely to be relieved post-vaccination than females. This finding could be due to the fact that males are more likely to be infected with COVID-19 (28) and are less likely to engage in preventive behavior than females $(29,30)$.

Inconsistent with previous studies, the results showed that the participants' anxiety about the vaccine was not eased even after being vaccinated (25). Although clinical trials support the safety and efficacy of the Oxford-AstraZeneca and Pfizer vaccines, both of which were commonly used in the KSA during the study period $(31,32)$, reported cases of thrombosis and thrombocytopenia syndrome that occurred following immunization with the Oxford-AstraZeneca vaccine $(33,34)$ could have provoked anxiety and eroded public confidence. Post-vaccination side effects might have also further contributed to feelings of anxiety post-vaccination. Thereby, informing the public on what to expect after vaccination can help in dispelling myths and lowering anxiety about the vaccine (35). Two-way communication that allows and encourages the public to ask questions could ensure that actual rather than assumed questions are adequately addressed (36).

Additionally, in countries such as the KSA where vaccination is mandatory, feelings of anxiety might not necessarily be eased post-vaccination. One plausible reason is that enforcement undermines faith in the government while also signaling that the government does not trust the individual to uphold the social norm of protecting others (37). As a result, the distrust expressed by law enforcement implies low expectations of peoples' behavior. From the perspective of citizens, this might lead to a mutually distrustful relationship $(38,39)$ that promotes vaccination reluctance. Furthermore, enforcement may diminish the beneficial conformism-based impacts of others who have been vaccinated. This is because individuals 
TABLE 2 | Logistic regression estimates of factors associated with feeling relieved after COVID-19 vaccination $(N=1,058)$.

\begin{tabular}{|c|c|c|c|}
\hline Variable & AOR & $95 \% \mathrm{Cl}$ & $p$-value \\
\hline \multicolumn{4}{|l|}{ Age (years) } \\
\hline \multicolumn{4}{|l|}{$18-29$ (ref) } \\
\hline 30-39 & 1.668 & $0.914-3.043$ & $0.096^{*}$ \\
\hline $40-49$ & 1.712 & $0.912-3.213$ & $0.094^{*}$ \\
\hline $50-59$ & 2.062 & $0.998-4.260$ & $0.051^{*}$ \\
\hline$\geq 60$ & 2.007 & $0.800-5.033$ & 0.138 \\
\hline \multicolumn{4}{|l|}{ Gender } \\
\hline \multicolumn{4}{|l|}{ Female (ref) } \\
\hline Male & 1.380 & $0.981-1.943$ & $0.064^{*}$ \\
\hline \multicolumn{4}{|l|}{ Marital status } \\
\hline \multicolumn{4}{|l|}{ Unmarried (ref) } \\
\hline Married & 0.905 & $0.608-1.349$ & 0.625 \\
\hline \multicolumn{4}{|l|}{ Educational level } \\
\hline \multicolumn{4}{|l|}{ High school or below (ref) } \\
\hline University degree & 0.667 & $0.443-1.003$ & $0.051^{*}$ \\
\hline Postgraduate degree & 0.712 & $0.452-1.121$ & 0.142 \\
\hline \multicolumn{4}{|l|}{ Employment status } \\
\hline \multicolumn{4}{|l|}{ Government employee (ref) } \\
\hline Private sector employee & 0.734 & $0.473-1.141$ & 0.170 \\
\hline Students & 3.902 & $1.674-9.096$ & $0.002^{\star \star \star}$ \\
\hline Unemployed & 1.124 & $0.533-2.373$ & 0.758 \\
\hline Retired & 1.240 & $0.781-1.968$ & 0.361 \\
\hline \multicolumn{4}{|l|}{$\begin{array}{l}\text { Suffer from } \\
\text { chronic illness }\end{array}$} \\
\hline \multicolumn{4}{|l|}{ No (ref) } \\
\hline Yes & 1.070 & $0.760-1.506$ & 0.700 \\
\hline \multicolumn{4}{|l|}{$\begin{array}{l}\text { Smoker } \\
\text { (cigarettes or shisha) }\end{array}$} \\
\hline \multicolumn{4}{|l|}{ No (ref) } \\
\hline Yes & 1.284 & $0.882-1.870$ & 0.193 \\
\hline \multicolumn{4}{|l|}{$\begin{array}{l}\text { Infected with COVID-19 } \\
\text { before vaccination }\end{array}$} \\
\hline \multicolumn{4}{|l|}{ No (ref) } \\
\hline Yes & 1.089 & $0.708-1.675$ & 0.698 \\
\hline \multicolumn{4}{|c|}{$\begin{array}{l}\text { Feeling anxious about the } \\
\text { COVID-19 vaccine before } \\
\text { receiving it }\end{array}$} \\
\hline \multicolumn{4}{|l|}{ No (ref) } \\
\hline Yes & 0.220 & $0.160-0.302$ & $0.000^{\star \star \star}$ \\
\hline \multicolumn{4}{|c|}{$\begin{array}{l}\text { Main source of } \\
\text { information } \\
\text { about COVID-19 vaccines }\end{array}$} \\
\hline \multicolumn{4}{|c|}{$\begin{array}{l}\text { Official media/scientific or } \\
\text { medical websites (ref) }\end{array}$} \\
\hline Social media platforms & 0.569 & $0.371-0.875$ & $0.010^{* *}$ \\
\hline Friends and relatives & 0.839 & $0.456-1.544$ & 0.573 \\
\hline Have no information & 0.408 & $0.221-0.752$ & $0.004^{\star \star \star}$ \\
\hline \multicolumn{4}{|l|}{$\begin{array}{l}\text { Number of doses } \\
\text { received so far }\end{array}$} \\
\hline \multicolumn{4}{|l|}{ One (ref) } \\
\hline Two & 2.278 & $1.630-3.182$ & $0.000^{\star \star \star}$ \\
\hline
\end{tabular}

(Continued)
TABLE 2 | Continued

\begin{tabular}{|c|c|c|c|}
\hline Variable & AOR & $95 \% \mathrm{Cl}$ & $p$-value \\
\hline \multicolumn{4}{|c|}{$\begin{array}{l}\text { Had a COVID-19 } \\
\text { breakthrough infection }\end{array}$} \\
\hline \multicolumn{4}{|l|}{ No (ref) } \\
\hline Yes & 0.977 & $0.565-1.689$ & 0.934 \\
\hline \multicolumn{4}{|l|}{$\begin{array}{l}\text { Had reaction to the } \\
\text { vaccine }\end{array}$} \\
\hline \multicolumn{4}{|l|}{ No side effects at all (ref) } \\
\hline Mild side effects & 0.848 & $0.572-1.257$ & 0.411 \\
\hline Moderate side effects & 0.595 & $0.382-0.926$ & $0.021^{\star *}$ \\
\hline Severe side effects & 0.288 & $0.165-0.504$ & $0.000^{\star \star \star}$ \\
\hline
\end{tabular}

who initially agree to get vaccinated may convey a favorable signal about their desire to collaborate as well as their trust in the vaccine's safety and effectiveness. Conversely, compliance with mandated vaccination conveys a considerably weaker signal. However, if vaccination desire is inadequate to generate cumulative gains in compliance, enforcement will be necessary (10).

Unsurprisingly, the results also showed that people who sourced their COVID-19 vaccine information from social media were less likely to feel relieved post-vaccination. Uncertainty and doubts fueled by rumors and myths surrounding vaccines link to infertility, harm, and altering the DNA can build on feelings of discomfort and anxiety post-vaccination (40).

The main limitations of this study include the use of an online survey that might have impacted the study's generalizability, the cross-sectional design, and lack of data on non-respondents. The results are only applicable to this context and may differ among other populations due to different vaccine policies, laws, and regulations. The social distancing regulations favor the use of online platforms in data collection, however using snowball sampling technique via social media platforms would have affected the representativeness of the sample. Moreover, this study does not imply causality, given that no causal identification methods were employed for analysis. A further limitation is that we have not examined the source of feeling "unrelieved," nor have we studied the psychological components which might have impacted these feelings.

\section{CONCLUSION}

Although safe and effective COVID-19 vaccines are now being administered across the KSA along with announcements that vaccines are 95\% effective, doubts and concerns surrounding vaccination remain a challenge. Knowledge about people's experience post-vaccination in the real world remains scarce. Our study disclosed that most of the Saudi population (around 66\%) feel relieved after receiving the mandatory COVID-19 
vaccine. We found that female gender, relying on social media for information concerning COVID-19 vaccines, and feeling anxious about the vaccine prior to vaccination were associated with a lack of relief post-vaccination. Individuals' attitudes toward COVID-19 vaccines may not necessarily alter even post-vaccination. Although mandatory vaccination policies can significantly contribute to achieving herd immunity, public confidence toward vaccines might be eroded and might in turn impose significant challenges in future pandemic efforts.

\section{DATA AVAILABILITY STATEMENT}

The datasets generated and/or analyzed during the current study are not publicly available due to privacy and confidentiality agreements as well as other restrictions but are available from the corresponding author on reasonable request.

\section{ETHICS STATEMENT}

All procedures performed in this study involving human participants complied with the institutional and/or national research committee ethical standards and the 1964 Helsinki Declaration and subsequent amendments or equivalent ethical standards. This research has been reviewed and given a favorable opinion by King Abdulaziz University. The study was designed and conducted according to the ethical principles established by King Abdulaziz University. Therefore, ethical approval was

\section{REFERENCES}

1. OECD. Access to COVID-19 Vaccines: Global Approaches in a Global Crisis. OECD Publishing (2021). Available online at: https://www.oecd-ilibrary. org/social-issues-migration-health/access-to-covid-19-vaccines-globalapproaches-in-a-global-crisis_c6a18370-en (accessed September 22, 2021).

2. OECD. Enhancing Public Trust in COVID-19 Vaccination: The Role of Governments 2021. Available online at: https://www.oecd.org/coronavirus/ policy-responses/enhancing-public-trust-in-covid-19-vaccination-the-roleof-governments-eae0ec5a/ (accessed October 6, 2021).

3. Sandhofer MJ, Robak O, Frank H, Kulnig J. Vaccine hesitancy in Austria. Wiener Klinische Wochenschrift. (2017) 129:5964. doi: 10.1007/s00508-016-1062-1

4. Riad A, Huang Y, Abdulqader H, Morgado M, Domnori S, Košč́k $\mathrm{M}$, et al. Universal predictors of dental students' attitudes towards COVID-19 vaccination: machine learning-based approach. Vaccines. (2021) 9:1158. doi: 10.3390/vaccines9101158

5. Kateeb E, Danadneh M, Pokorná A, Klugarová J, Abdulqader $\mathrm{H}$, Klugar $\mathrm{M}$, et al. Predictors of willingness to receive COVID-19 vaccine: cross-sectional study of Palestinian dental students. Vaccines. (2021) 9:954. doi: 10.3390/vaccines 90 90954

6. Qattan A, Alshareef N, Alsharqi O, Al Rahahleh N, Chirwa GC, Al-Hanawi MK. Acceptability of a COVID-19 vaccine among healthcare workers in the Kingdom of Saudi Arabia. Front Med. (2021) 8:83. doi: 10.3389/fmed.2021.6 44300

7. Wouters OJ, Shadlen KC, Salcher-Konrad M, Pollard AJ, Larson HJ, Teerawattananon Y, et al. Challenges in ensuring global access to COVID-19 vaccines: production, affordability, allocation, and deployment. Lancet. (2021) 37:1023-34. doi: 10.1016/S0140-6736(21)00306-8

8. De Figueiredo A, Simas C, Karafillakis E, Paterson P, Larson HJ. Mapping global trends in vaccine confidence and investigating barriers to vaccine obtained from the Biomedical Ethics Research Committee, Faculty of Medicine, King Abdulaziz University (Ref-380-21). The participants provided their online informed consent to participate in this study.

\section{AUTHOR CONTRIBUTIONS}

MA-H: conceptualization, data curation, formal analysis, methodology, project administration, software, supervision, and funding acquisition. MA-H, NA, and RE-S: validation, writingoriginal draft preparation, writing-review, and editing. All authors have read and agreed to the published version of the manuscript.

\section{FUNDING}

This research was funded by the Institutional Fund Projects under grant number IFPRC-207-121-2020. The funders had no role in the study design, data collection and analysis, decision to publish, or preparation of the manuscript.

\section{ACKNOWLEDGMENTS}

The authors gratefully acknowledge technical and financial support from the Ministry of Education and King Abdulaziz University, Jeddah, Saudi Arabia. uptake: a large-scale retrospective temporal modelling study. Lancet. (2020) 396:898-908. doi: 10.1016/S0140-6736(20)31558-0

9. WHO. COVID-19 Vaccines: Safety Surveillance Manual. Geneva: World Health Organization (2021).

10. Schmelz K, Bowles S. Overcoming COVID-19 vaccination resistance when alternative policies affect the dynamics of conformism, social norms, and crowding out. Proc Natl Acad Sci USA. (2021) 118:e2104912118. doi: 10.1073/pnas.21049 12118

11. Ropero-Álvarez A, Whittembury A, Bravo-Alcántara P, Kurtis H, DanovaroHolliday M, Velandia-Gonzalez M. Events supposedly attributable to vaccination or immunization during pandemic influenza A (H1N1) vaccination campaigns in Latin America and the Caribbean. Vaccine. (2015) 33:187-92. doi: 10.1016/j.vaccine.2014.10.070

12. Sturkenboom MC. The narcolepsy-pandemic influenza story: can the truth ever be unraveled? Vaccine. (2015) 33:B613. doi: 10.1016/j.vaccine.2015.03.026

13. Petersen MB, Bor A, Jørgensen F, Lindholt MF. Transparent communication about negative features of COVID-19 vaccines decreases acceptance but increases trust. Proc Natl Acad Sci USA. (2021) 118:e2024597118. doi: 10.1073/pnas.20245 97118

14. KFF. KFF COVID-19 Vaccine Monitor: February 2021 (2021). Available online at: https://www.kff.org/coronavirus-covid-19/poll-finding/kff-covid19-vaccine-monitor-february-2021/ (accessed October 13, 2021).

15. Alfageeh EI, Alshareef N, Angawi K, Alhazmi F, Chirwa GC. Acceptability of a COVID-19 vaccine among the Saudi population. Vaccines. (2021) 9:226. doi: 10.3390/vaccines9030226

16. Fayed AA, Al Shahrani AS, Almanea LT, Alsweed NI, Almarzoug LM, Almuwallad RI, et al. Willingness to receive the COVID-19 and seasonal influenza vaccines among the Saudi population and vaccine uptake during the initial stage of the national vaccination campaign: 
a cross-sectional survey. Vaccines. (2021) 9:765. doi: 10.3390/vaccines 90 70765

17. COVIDVAX. Live COVID-19 Vaccination Tracker 2021. Available online at: https://covidvax.live/location/sau (accessed December 4, 2021).

18. Alshareef N, Yunusa I, Al-Hanawi MK. The Influence of COVID-19 information sources on the attitudes and practices toward COVID-19 among the general public of Saudi Arabia: cross-sectional online survey study. JMIR Public Health Surveill. (2021) 7:e28888. doi: 10.2196/28888

19. Al-Hanawi MK, Angawi K, Alshareef N, Qattan A, Helmy HZ, Abudawood Y, et al. Knowledge, attitude and practice toward COVID-19 among the public in the Kingdom of Saudi Arabia: a cross-sectional study. Front Public Health. (2020) 8:217. doi: 10.3389/fpubh.2020.00217

20. GASTAT. General Authority for Statistics: The Kingdom of Saudi Arabia 2021. Available online at: https://www.stats.gov.sa/en/node (accessed June 4, 2021).

21. RAOSOFT. Sample Size Calculator 2021. Available online at: http://www. raosoft.com/samplesize.html (accessed June 4, 2021).

22. WHO. Immunization Stress-Related Response: A Manual for Program Managers and Health Professionals to Prevent, Identify and Respond to Stress-Related Responses Following Immunization. World Health Organization (2019). Available online at: https://apps.who.int/iris/bitstream/handle/10665/ 330277/9789241515948-eng.pdf (accessed June 1, 2021).

23. Menni C, Valdes AM, Freidin MB, Sudre CH, Nguyen LH, Drew $\mathrm{DA}$, et al. Real-time tracking of self-reported symptoms to predict potential COVID-19. Nat Med. (2020) 26:1037-40. doi: 10.1038/s41591-020-0 916-2

24. Jeśkowiak I, Wiatrak B, Grosman-Dziewiszek P, Szelag A. The incidence and severity of post-vaccination reactions after vaccination against COVID-19. Vaccines. (2021) 9:502. doi: 10.3390/vaccines 9050502

25. Hatmal MmM, Al-Hatamleh MA, Olaimat AN, Hatmal M, AlhajQasem DM, Olaimat TM, et al. Side effects and perceptions following COVID-19 vaccination in Jordan: a randomized, crosssectional study implementing machine learning for predicting severity of side effects. Vaccines. (2021) 9:556. doi: 10.3390/vaccines 90 60556

26. Fetters L, Tilson J. Evidence Based Physical Therapy. 2nd ed. Philadelphia, CA: Davis (2018).

27. Malik A, McFadden S, Elharake J, Omer S. Determinants of COVID-19 vaccine acceptance in the US. EClinicalMedicine. (2020) 26:100495. doi: 10.1016/j.eclinm.2020.100495

28. Chen N, Zhou M, Dong X, Qu J, Gong F, Han Y, et al. Epidemiological and clinical characteristics of 99 cases of 2019 novel coronavirus pneumonia in Wuhan, China: a descriptive study. Lancet. (2020) 395:507-13. doi: 10.1016/S0140-6736(20)3 0211-7

29. Galasso V, Pons V, Profeta P, Becher M, Brouard S, Foucault M. Gender differences in COVID-19 attitudes and behavior: panel evidence from eight countries. Proc Natl Acad Sci USA. (2020) 117:2728591. doi: 10.1073/pnas.2012520117

30. Peckham H, de Gruijter NM, Raine C, Radziszewska A, Ciurtin C, Wedderburn LR, et al. Male sex identified by global COVID-19 meta-analysis as a risk factor for death and ITU admission. Nat Commun. (2020) 11:110. doi: 10.1038/s41467-020-19741-6
31. Alley SJ, Stanton R, Browne M, To QG, Khalesi S, Williams SL, et al. As the pandemic progresses, how does willingness to vaccinate against COVID-19 evolve? Int J Environ Res Public Health. (2021) 18:797. doi: 10.3390/ijerph18020797

32. Folegatti PM, Ewer KJ, Aley PK, Angus B, Becker S, BelijRammerstorfer S, et al. Safety and immunogenicity of the ChAdOx1 nCoV-19 vaccine against SARS-CoV-2: a preliminary report of a phase 1/2, single-blind, randomised controlled trial. Lancet. (2020) 396:467-78. doi: 10.1016/S0140-6736(20)31604-4

33. Wise J. COVID-19: European countries suspend use of OxfordAstraZeneca vaccine after reports of blood clots. BMJ. (2021) 372:n699. doi: 10.1136/bmj.n699

34. Vogel G, Kupferschmidt K. 'It's a very special picture.'Why vaccine safety experts put the brakes on AstraZeneca's COVID-19 vaccine. Science. (2021) 17. doi: 10.1126/science.abi5259

35. Jayadevan R, Shenoy RS, Anithadevi T. Survey of symptoms following COVID-19 vaccination in India. medRxiv. (2021). doi: 10.1101/2021.02.08.21251366

36. Leask J. Restoring confidence after the covid-19 Oxford/AstraZeneca vaccine pause will be an uphill battle BMJ opinion (2021). Available online at: https:// blogs.bmj.com/bmj/2021/03/18/restoring-confidence-after-the-covid-

19-oxford-astrazeneca-vaccine-pause-will-be-an-uphill-battle/ (accessed November 22, 2021).

37. Sliwka D. Trust as a signal of a social norm and the hidden costs of incentive schemes. Am Econ Rev. (2007) 97:999-1012. doi: 10.1257/aer.97.3.999

38. Fehr E, Rockenbach B. Detrimental effects of sanctions on human altruism. Nature. (2003) 422:137-40. doi: 10.1038/nature01474

39. Bartling B, Fehr E, Schmidt KM. Screening, competition, and job design: economic origins of good jobs. Am Econ Rev. (2012) 102:83464. doi: $10.1257 /$ aer.102.2.834

40. CDC. Myths and Facts About COVID-19 Vaccines: Centers for Disease Control and Prevention. (2021). Available online at: https://www.cdc.gov/coronavirus/ 2019-ncov/vaccines/facts.html (accessed September 9, 2021).

Conflict of Interest: The authors declare that the research was conducted in the absence of any commercial or financial relationships that could be construed as a potential conflict of interest.

Publisher's Note: All claims expressed in this article are solely those of the authors and do not necessarily represent those of their affiliated organizations, or those of the publisher, the editors and the reviewers. Any product that may be evaluated in this article, or claim that may be made by its manufacturer, is not guaranteed or endorsed by the publisher.

Copyright (C) 2022 Al-Hanawi, Alshareef and El-Sokkary. This is an open-access article distributed under the terms of the Creative Commons Attribution License (CC $B Y)$. The use, distribution or reproduction in other forums is permitted, provided the original author(s) and the copyright owner(s) are credited and that the original publication in this journal is cited, in accordance with accepted academic practice. No use, distribution or reproduction is permitted which does not comply with these terms. 